\title{
Urban Seismic Networks, Structural Health and Cultural Heritage Monitoring: The National Earthquakes Observatory (INGV, Italy) Experience
}

\begin{abstract}
Antonino D'Alessandro*, Antonio Costanzo, Chiara Ladina, Fabrizia Buongiorno, Marco Cattaneo, Sergio Falcone, Carmelo La Piana, Simone Marzorati, Salvatore Scudero, Giovanni Vitale, Salvatore Stramondo and Carlo Doglioni
\end{abstract}

Istituto Nazionale di Geofisica e Vulcanologia, Osservatorio Nazionale Terremoti, Rome, Italy

A multiscale approach to the monitoring of earthquakes and their effects can represent an effective tool for the reduction of seismic risk. Devoted monitoring networks are essential to cope with the seismic emergency in urban areas, to assess the damage scenarios,
OPEN ACCESS

Edited by:

Michele Palermo,

University of Bologna, Italy

Reviewed by:

Michele Betti,

University of Florence, Italy

Antonio Maria D'Altri,

University of Bologna, Italy

*Correspondence:

Antonino D'Alessandro

antonino.dalessandro@ingv.it

Specialty section:

This article was submitted to

Earthquake Engineering,

a section of the journal

Frontiers in Built Environment

Received: 13 August 2019 Accepted: 08 October 2019 Published: 05 November 2019

Citation:

D'Alessandro A, Costanzo A, Ladina C, Buongiorno F, Cattaneo M, Falcone S, La Piana C, Marzorati S, Scudero S, Vitale G, Stramondo S and Doglioni C (2019) Urban Seismic

Networks, Structural Health and Cultural Heritage Monitoring: The National Earthquakes Observatory

(INGV, Italy) Experience.

Front. Built Environ. 5:127.

doi: 10.3389/fbuil.2019.00127 which are useful for the preservation of the strategic functions and services and to improve the community resilience to earthquakes. The National Earthquake Observatory, Italian Institute for Geophysics and Volcanology (ONT-INGV, Italy), has been recently involved in several projects devoted to the reduction of seismic risk by means of the implementation of urban-scale and building-scale monitoring networks. Such systems represent a necessary support for the well-established national seismic network. All these approaches (country, urban, and building scale) could be framed within of a unique system in which each part holds different tasks, with the common final objective of the earthquake risk reduction. In this paper different approaches, experiences and potential capabilities on urban seismic networks, structural health and cultural heritage monitoring implemented in Italy by the ONT-INGV will be presented, with the ultimate goal of achieving an effective integrated multi-scale system.

Keywords: urban seismic networks, structural health monitoring, cultural heritage monitoring, seismic hazard assessment, seismic risk reduction

\section{INTRODUCTION}

In the last decade the awareness of the seismic risk, also supported by the technological development, resulted in the increasing interest in the monitoring of the exposed urban centers and their built heritage. The recent seismic history of Italy proves that the effects of large earthquakes are often destructive in the highly vulnerable urban areas, and especially with reference to the huge Italian cultural and historic heritage. Those are the cases of Umbria and Marche earthquake in 1997 (Spence and D'Ayala, 2018), L'Aquila in 2009 (D'Ayala and Paganoni, 2011; Lagomarsino, 2012), Emilia-Romagna in 2012 (Andreini et al., 2014; Valente et al., 2017) and, more recently, Central Italy during the 2016-2017 seismic sequence (Caserta et al., 2016; Fiorentino et al., 2018). Devoted monitoring networks are essential to cope with the emergency in urban areas, to assess the damage scenarios which are useful for the preservation of the strategic functions and services (Emergency Limit Condition), and to improve the community resilience to earthquakes (Dolce et al., 2019). 


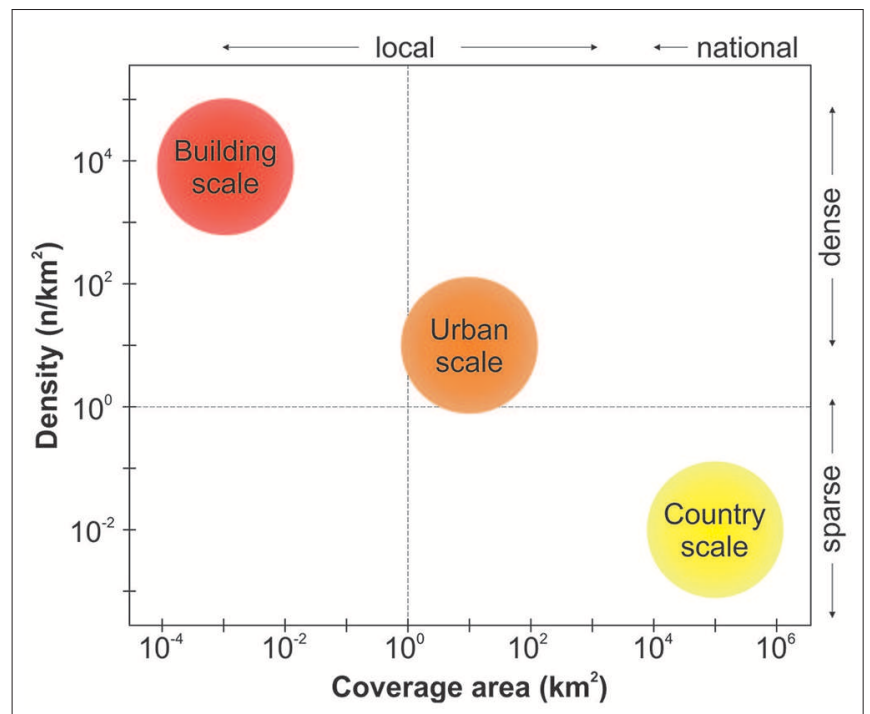

FIGURE 1 | Schematic representation of the country-scale, urban-scale, and building-scale monitoring networks in terms of coverage area and density of nodes.

Even more, the targeted monitoring of the critical structures, such as Strategic Public Buildings (SPB) and cultural heritage sites, allow the mitigation of the seismic risk effects and the enhancement of the emergency response.

The aims of urban-scale and the building-scale monitoring networks are different with respect the "traditional" countryscale networks which are intended for earthquake observation and seismological studies. The urban-scale networks are devoted to the mapping of the earthquake intensity and to the implementation of early warning systems; the buildingscale networks are mainly conceived for the structural health monitoring and also for on-site warning systems.

Moreover, they have really distinct characteristics in term of coverage areas and densities of nodes since they differ even of some order of magnitude (Figure 1). From Figure 1 it can also be deduced that the number of nodes of a country-scale network can be one order of magnitude higher with respect the urbanscale, and the number of nodes of the latter can be, in turn, one order of magnitude higher of the building-scale. According to the different objectives of national scale and local scale networks, the quality (i.e., sensitivity and resolution) of the components (sensor and digitizer) employed in the latter network is not so impelling. The cost for a high-quality professional suite can be even 10 or 20 times higher than the basic one. For all these reasons, each type of network needs not only a specific technical design and planning, but also the accurate evaluation of temporal and economical costs.

Local-scale networks can be established in relatively short times and with limited costs with respect to the national ones. The National Earthquake Observatory, a department of the Italian Institute for Geophysics and Volcanology (ONT-INGV), contributed in the last years to the development of local networks in Italy. The activities were funded by through several projects in which the INGV was the principal investigator. In this paper we present the specific objectives, the results, and the potential future developments of these projects. Specifically, for each of the proposed approaches, we provide the design criteria, the architecture of the implemented systems, and show some of the results. We finally introduce the potential capabilities of an integrated multi-scale approach.

\section{URBAN SEISMIC NETWORK FOR POST-EARTHQUAKES RAPID DISASTER ASSESSMENT}

In such cases, the timely emergency operations are crucial to rescue people eventually trapped under collapsed buildings. The promptness and effectiveness of rescue operations in the immediate post-earthquake are often limited because the lack of information about the distribution of the earthquake intensity. The possibility to map the intensity with adequate resolution depends on the availability and on the spatial distribution of monitoring stations. As previously discussed, a national-scale network is too loose to address this issue (D'Alessandro et al., 2011), conversely, local-scale networks would represent the best solution. The possibility to establish local-scale networks has been favored by the technological development of the sensors (D'Alessandro and D'Anna, 2013), data transmission, computational power, and data storage capability. Various urban seismic networks have been developed worldwide in the last years, essentially based on miniaturized sensors (Cochran et al., 2009; Horiuchi et al., 2009; Chung et al., 2011; Clayton et al., 2012; D'Alessandro, 2014, 2016; D’Alessandro et al., 2014, 2018a,b; Nof et al., 2019). The main characteristics of local networks based on micro electro-mechanical systems (MEMS) sensors are high-density of nodes, real-time transmission, and low-costs (see Scudero et al., 2018 and D’Alessandro et al., 2019b for a complete review).

We present the urban networks implemented by the Palermo ONT-INGV in some towns the last years realized within the project called MEMS: "Monitoring Earthquakes through MEMS Sensors." funded by the Italian Minster for Research. The urban networks have been designed and installed in agreement with the local municipalities and mainly conceived for the fast assessment of earthquake-induced damage (Figure 2). This is achieved through the production of "shakemaps," which are maps of ground motion and shaking intensity elaborated near-real-time after a significant earthquake. They are seismologically based interpolations and combine observed data and seismological knowledge to produce maps of peak ground motion (PGM).

The monitoring station consists of a single-board computer which manages the acquisition and the transmission of data through a dedicated code (Figure 3). The sensor is a 3-axial MEMS capacitive accelerometer with digital output which is sampled at a frequency of $200 \mathrm{~Hz}$. This sensor is suitable for dynamic accelerations in the range of $\pm 2 \mathrm{~g}$, it is characterized by a measure resolution of $76.3 \mu \mathrm{g}$, and white noise of $280 \mu \mathrm{g}$. Three waveform files, one for each component, are written in miniSEED format. This is standardized protocol for the exchange 


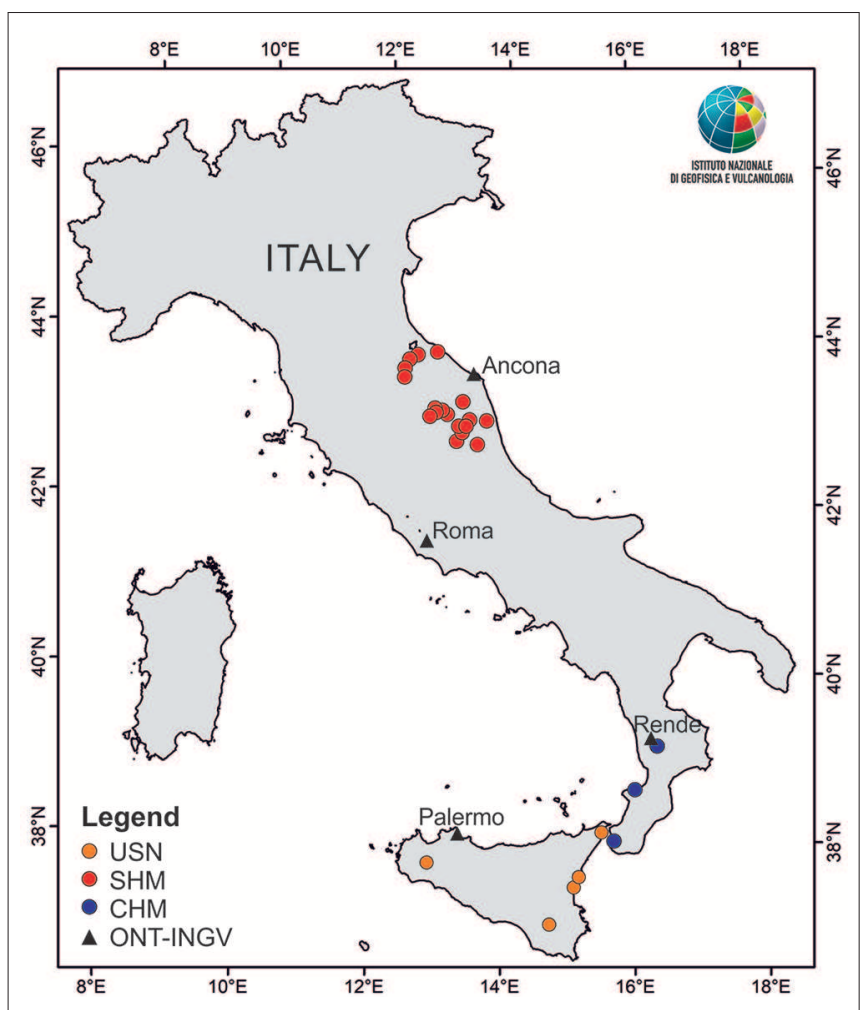

FIGURE 2 | Map of the networks developed by INGV-ONT. USN, urban seismic networks; SHM, structural health monitoring of the PSBs; $\mathrm{CHM}$, cultural heritage monitoring; ONT-INGV, Italian earthquake observatory office.

of earthquake data used by seismologists worldwide (Ahern et al., 2007). The transmission of these files exploits a ringserver conceived by the Incorporated Research Institutions for Seismology (IRIS) which runs continuously and cyclically. The synchronization of the signals between the various stations is fundamental and is ensured by a GPS. Alternatively, to the GPS antenna, in particular in the sites where the sky view is limited, the connection to an NTP server (Network Time Protocol) provides the desired synchronization. Finally, the monitoring station carries a 5,200 mAh power bank (UPS) to stabilize the energy supply and to provide power in case of temporary black-out.

The network topology chosen for these networks is a star network where each node is connected to a central hub with a point-to-point connection. This arrangement has been chosen because it complies both flexibility and reliability. From the hub can depart $n$ linear connections, therefore further nodes (i.e., monitoring stations) can be added or removed without disrupt the network. Moreover, two or more end-points can be merged in a sub-network and, similarly, two or more networks can be merged into a unique network simply connecting their hubs. The transmission exploits the internet connection and every node can be accessed remotely to fix eventual problem or to perform eventual update of the software. The weak aspect of this kind of networks is that this central hub represents the single point of failure: in case of failing, it would stop the entire system from working. For this reason, all the nodes of all the networks send their signals to the seismic room located in Palermo where the signals are recomposed by means of specific software, and where they can be managed and archived. The hardware units guarantee the redundancy of the system and are designed for long-term endurance. The network management software is SeisComP3 (https://www.seiscomp3.org/) developed in Germany by the geoscience research center (GFZ, Potsdam). The program consists of various modules for acquisition, processing, interactive analysis, and data distribution. The seismic room receives the miniSEED files from the stations and recomposes them into single daily traces (one trace per component) which is then archived. The system can also operate as ringserver, and distribute the data to the seismic rooms of INGV and other institutions.

The full details of the MEMS-based monitoring station, about the specification of the sensor, on the configuration of the network, and about the seismic room can be found in D'Alessandro et al. (2017, 2018a,b, 2019a).

The set-up and the arrangement of the monitoring stations at the sites have been planned considering the planimetry of each building. The preferred location is at the base of the building since it provides an almost unaltered record of the input motion. Example of urban seismic network implemented in Ragusa town is showed in Figure 3. All the sensors were leveled on the horizontal plane and the horizontal components accurately oriented along the N-S and E-W directions in order to have a unique reference system for the signals in every station.

As an example, we report the signals recorded at the one of the monitoring sites after the $\mathrm{M}_{\mathrm{L}} 3.1$ earthquake occurred on October 30th, 2018 in the municipality of S. Ninfa (Sicily) where the monitoring station is hosted in the town hall. The Figure 4 shows the acceleration signals (sampling frequency is $250 \mathrm{~Hz}$ ) for the three components filtered in the band between 1 and $35 \mathrm{~Hz}$. The earthquake was detected with a good signalto-noise ratio, and the arrivals of the various seismic phases are clearly recognizable, with different values of amplitude and frequency. The peak ground acceleration (PGA) is a $0.069 \mathrm{~m} / \mathrm{s}^{2}$ for the vertical component, 0.159 and $0.144 \mathrm{~m} / \mathrm{s}^{2}$ for the NS and EW components, respectively (Figure 4). The spectrograms show higher power between 5 and $35 \mathrm{~Hz}$ in the vertical component, and between few $\mathrm{Hz}$ and about $25 \mathrm{~Hz}$ for the horizontal components. In these latter, part of the frequency content is ascribable to resonance phenomena of the building such as the long-lasting peak at about $4 \mathrm{~Hz}$ (Figure 4).

The main aim of urban seismic networks is a rapid evaluation of earthquake damage through the automatic production of shakemaps. However, also some other objectives can be accomplished such as seismic microzonation, sitespecific earthquake early warning system (EEW) and automatic procedures of mapping and research system. In a future evolution, the implemented urban seismic networks could represent only a step in a continuous chain of actions (Figure 5). The on-site EEW is a system able to provide an alert in the aftermath of a strong, local earthquake. The seismic monitoring station at each site detects the P-wave arrivals using an automatic earthquake recognition procedure and estimates the intensity of 


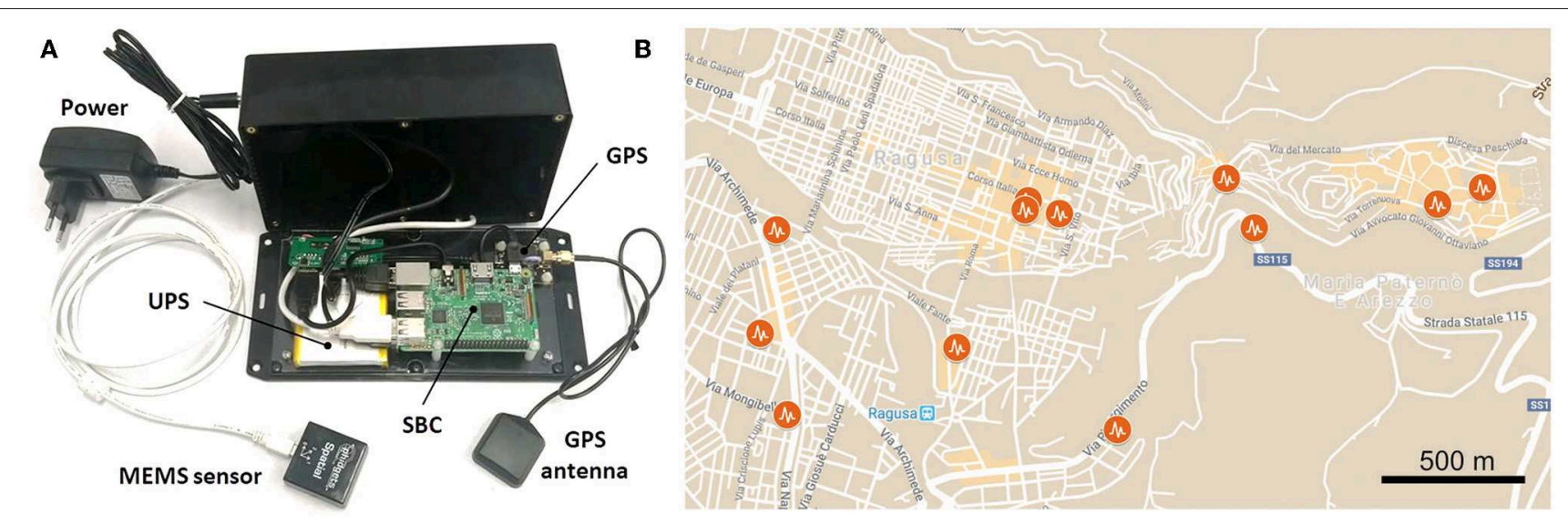

FIGURE 3 | (A) The seismic monitoring station implemented in the framework of MEMS project; (B) Maps of the urban seismic network in Ragusa; at present (August 2019) it consists of 13 nodes, but a further expansion is planned.

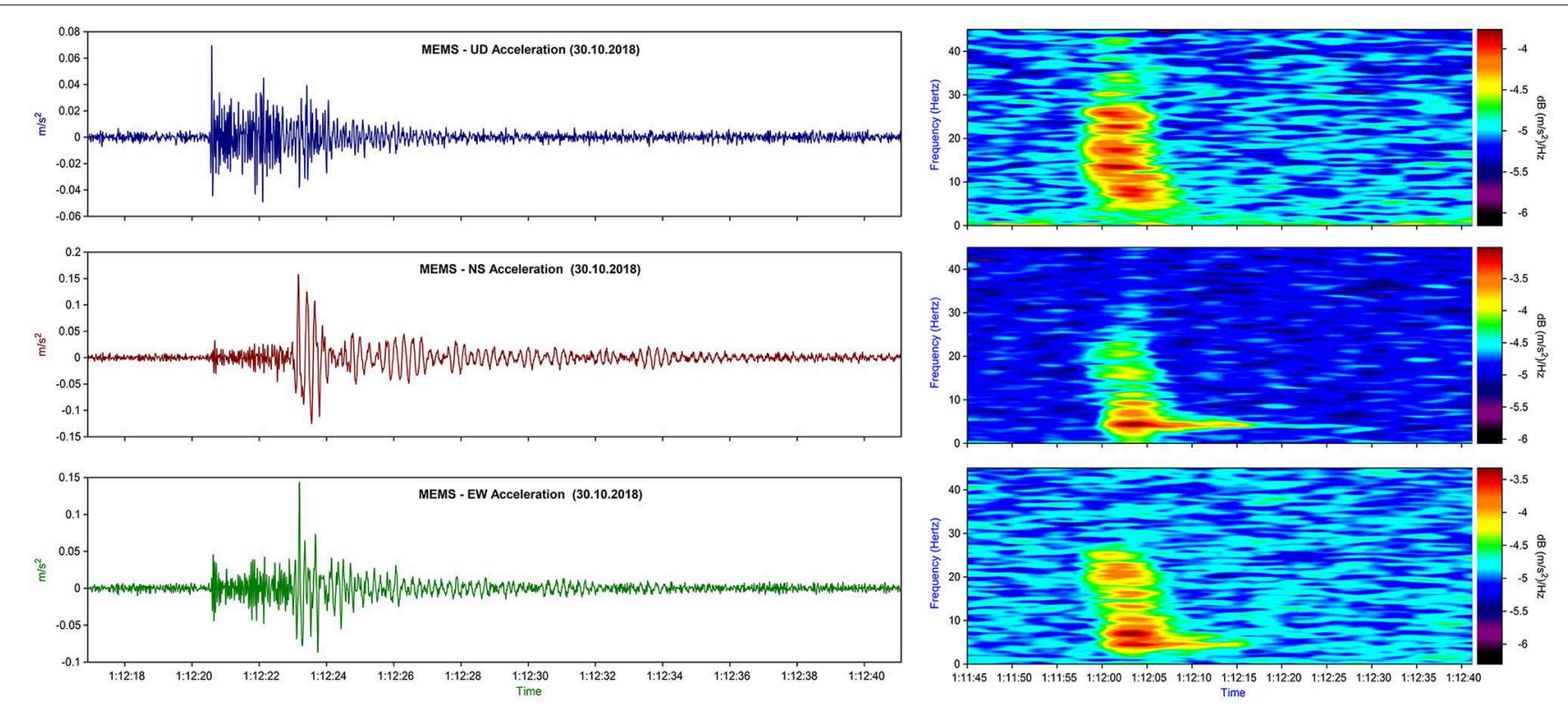

FIGURE 4 | Seismic signals (Left), band-pass filtered acceleration between 1 and $35 \mathrm{~Hz}$, recorded at the MEMS station located in S. Ninfa after the ML 3.1 earthquake occurred on October 30th, 2018 and located $5 \mathrm{~km}$ away from the monitoring station (30 s time window), and relative spectrograms (Right).

the impending strong shakings in a few fractions of second. The warning can be issued before S-wave arrivals, taking advantage of the difference between the $\mathrm{P}$ and $\mathrm{S}$ waves velocities (see Satriano et al., 2011 for a complete review). The elaboration of the shake maps would be the following step and a further one could be an automated visual inspection system for survivor research performed by means of unmanned aerial vehicles (UAV) (Cannioto et al., 2017; Giordan et al., 2018; Zhu et al., 2019).

\section{STRUCTURAL HEALTH MONITORING FOR THE STRATEGIC PUBLIC BUILDINGS}

An earthquake can affect the state of health of a Strategic Public Building (SPB) with regard to the strength of the seismic action spread from soil to the structure. The real time acquisition systems of the modern seismic networks such as that of the ONTINGV allow to analyze seismic data recorded by a sensor few seconds after a seismic event. The installation of a sensor at the base of a structure supplies the shake of the ground, a basic data to compare with the damage limit state of a structure. The main advantage to have a sensor under a structure is the precise and detailed measurement of the shaking and not an inferred value of it, obtained by the focal parameters, the attenuation relationships and site effects assessment. This kind of monitoring is far less expensive, in term of implementation and management costs, with respect to a dense network of sensors installed at all floors of the structure. In perspective, this approach allows to expand and spread out the monitoring in vast areas of the territory, 


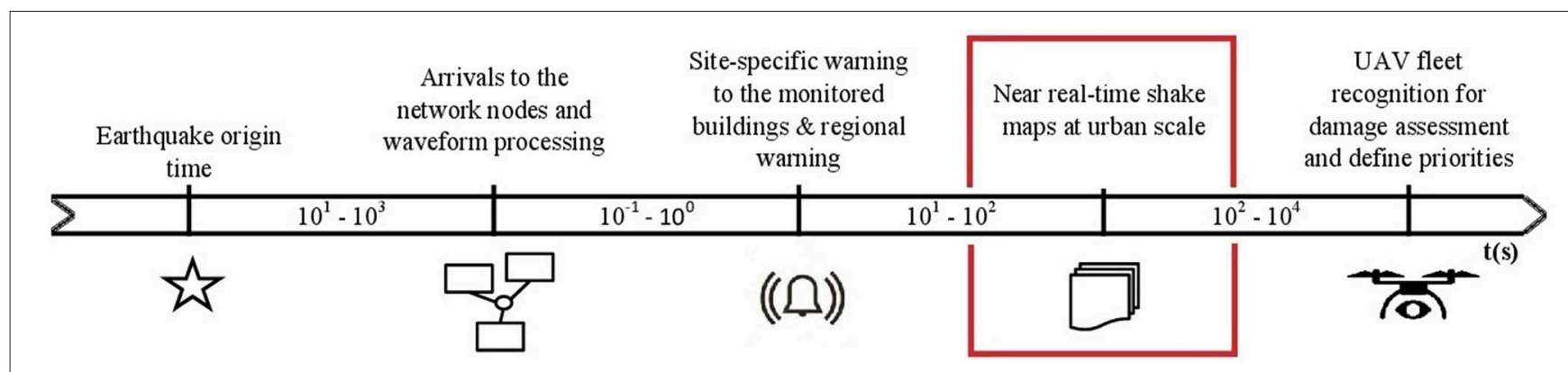

FIGURE 5 | General scheme and time progress bar (in seconds) of all the potential tasks of an urban seismic network; the post-earthquakes rapid disaster assessment task is highlighted in red.

covering numerous critical structures. Furthermore, this kind of infrastructure may represent the starting point for a more complete monitoring of the dynamical response of the buildings, inserting more sensors in the already instrumented buildings with a strategy similar to other experiences in Italy (Dolce et al., 2017).

In a decision support tool for seismic risk, the expected physical damage could be expressed in terms of quantitative and/or qualitative seismic parameters and vulnerability curves (Matassoni et al., 2017). The strong motion engineering parameters are quantitative measures of the ground motion. The widespread strong motion parameters are Peak Ground Acceleration (PGA) and Peak Ground Velocity (PGV) but other markers are used, such as elastic spectral quantities $(\mathrm{Sa})$, Arial Intensity or Housner Intensity to represent input for damage scenarios (Casolo, 2001; Chiauzzi et al., 2012). These parameters are directly calculated from accelerometric waveforms of the earthquake recorded at each single site of the network. Instead, the macroseismic intensity (I) is a qualitative value that describes the effects of the earthquake on the surface, starting from the observed damage on the natural territory and anthropic manufacts. An estimate of the macroseismic intensity may be obtained from accelerometric waveforms by means of empirical relationships, i.e., between PGA and I (Ambraseys, 1975; Trifunac and Brady, 1975; Margottini et al., 1992; Wald et al., 1999; Faenza and Michelini, 2010).

An assessment of the vulnerability of the buildings could be inferred from some characteristics of the structures (Lagomarsino and Giovinazzi, 2006; Matassoni et al., 2017), easily retrievable. The essential characteristics are function of the building, building material, state of preservation, height, date of construction. In many cases, one temporary ambient vibration measurement of the seismic noise at the top of the building improves the knowledge of the building (Crawford and Ward, 1964; Ward and Ward and Crawford, 1966; Gallipoli et al., 2003; Mucciarelli et al., 2004). In the case of a detached building the fundamental period of vibration and, in some case, also the period of higher modes could be extracted by a single measurement. The connection between buildings in an aggregate can affect the results and the periods of the vibrations represent a poor estimate, useful only for rapid and approximated communications of a damage scenario in near real time. Two synchronous seismic noise measurements can supply a preliminary identification of translational and torsional modes. A more complete description of the response of the structure is derived from the measurements at all floors together with a model of the design of the building (Regni et al., 2018). In all these approaches, the ground motion at the base of the structure is the fundamental input to calculate the response of the structure and the seismic risk. The direct measure of the shake already includes the contribution of the earthquake source, the propagation, the attenuation and the site effect.

In central eastern Italy, the Ancona headquarter of ONTINGV started to implement a seismic monitoring of SPB in the year 2013 in agreement with and by demand of the local Civil Protection of the Regione Marche authority. In the framework of two European Projects (IPA Adriatic Holistic and Readiness Interreg Italy-Croatia), two kinds of activity are performed: temporary measurements of ambient seismic noise and installation of permanent accelerometric stations. Moreover, data are collected about characteristics of the buildings and sites.

At least three seismic noise measurements are carried out at each site with velocimetric mobile seismic stations: a measure at the top of the structure, another at the base near the permanent accelerometric station and the last one outside the building on the soil. The measure at the top of the building is useful to estimate the fundamental period of vibration of the structure. At the first step, this information is useful to improve the knowledge of the structure response and then it could be compared with the resonance frequency of the soil assessed with the external measure to investigate potential soil-structure interactions. The measure near permanent the station helps to verify possible coupling between permanent sensor and structure.

The seismic noise is processed in terms of Power Spectral Density (PSD) (McNamara and McNamara and Buland, 2004) and Horizontal to Vertical Spectral Ratio (HVSR) (Nakamura, 1989) with mobile windows analysis. Also, the PSD and HVSR are computed after horizontal component rotation every $5^{\circ}$ from 0 to $180^{\circ}$ relative to geographic north. The results of the analysis are fundamental spectral peaks and the main direction of the vibration. If the shape of the structure is regular, also the longitudinal and the transversal spectral peaks can be recognized. Following the temporary measures, a permanent accelerometric station was installed at the base of the structure (Figure 2). The 
aim is to record the seismic input of the strong earthquakes and to estimate the potential damage. In general, the permanent station is equipped with a low cost and/or cost-effective MEMS accelerometer capable to record signals larger than $1 \mathrm{mg}$ with a good signal to noise ratio (Pierleoni et al., 2018). The sensors with these characteristics also allow the detection of body waves from small earthquakes and provide data useful to regional seismic monitoring and/or to the creation of shake maps too. Recently, in two cases, an experimental permanent sensor was installed at the top of the structure to collect raw data useful to calculate other engineering parameters like inter-floor drift and PGA ratio.

\begin{tabular}{|c|c|c|c|}
\hline \multicolumn{2}{|l|}{ Event ID: 8863681} & \multicolumn{2}{|c|}{ Magnitude: 6.5} \\
\hline \multicolumn{2}{|c|}{ Origin time: $2016-10-3006: 40: 17$} & \multirow{2}{*}{\multicolumn{2}{|c|}{$\begin{array}{l}\text { Nearest town: Norcia } \\
\text { Depth: } 9.2 \mathrm{~km}\end{array}$}} \\
\hline Lon E: 13.110700 & Lat $\mathrm{N}: 42.832199$ & & \\
\hline Site: MMO1 & & Analysis: $R$ & Picking: $M$ \\
\hline Parameter & Comp $z$ & Comp $N$ & CompE \\
\hline$P G A\left(\mathrm{~cm} / \wedge^{\wedge} \wedge 2\right)$ & 136.544 & 178.484 & 100.6 \\
\hline $\mathrm{PGV}(\mathrm{cm} / \mathrm{s} 2)$ & 9.48505 & 8.59108 & 4.50233 \\
\hline AI $\left(\mathrm{cm} / \mathrm{s}^{\wedge} 2\right)$ & 35.6818 & 49.991 & 14.8452 \\
\hline$H(\mathrm{~cm})$ & 31.6778 & 33.3683 & 19.6098 \\
\hline $\mathrm{Sa}(0.10)\left(\mathrm{cm} / \mathrm{s}^{\wedge} 2\right)$ & 315.218 & 497.123 & 248.537 \\
\hline $5 \mathrm{a}(0.30)\left(\mathrm{cm} / \mathrm{s}^{\wedge} 2\right)$ & 398.17 & 502.086 & 187.222 \\
\hline $\mathrm{Sa}(1)(\mathrm{cm} / \mathrm{s} \wedge 2)$ & 82.1419 & 99.1452 & 53.5612 \\
\hline $\mathrm{Sa}(3)\left(\mathrm{cm} / \mathrm{s}^{\wedge} 2\right)$ & 11.6019 & 22.206 & 10.8151 \\
\hline
\end{tabular}

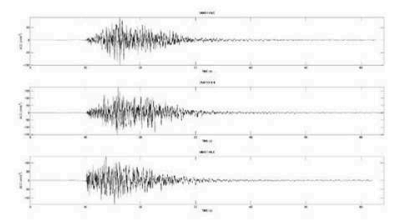

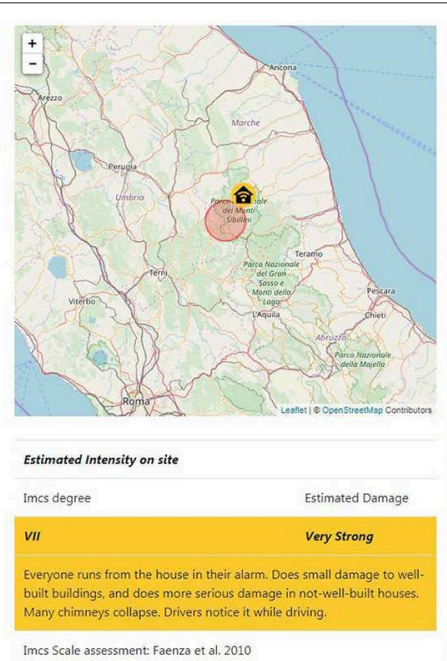

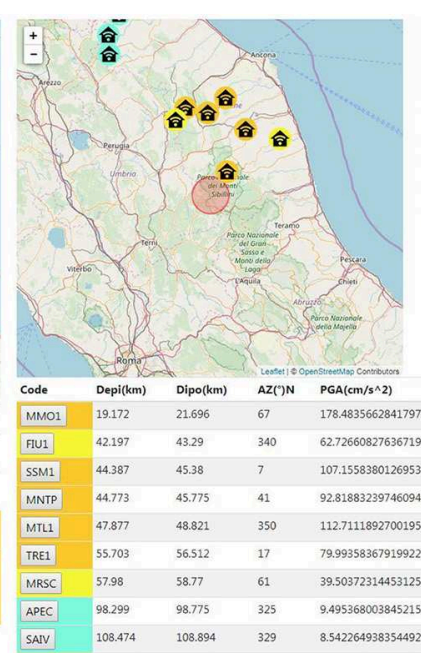

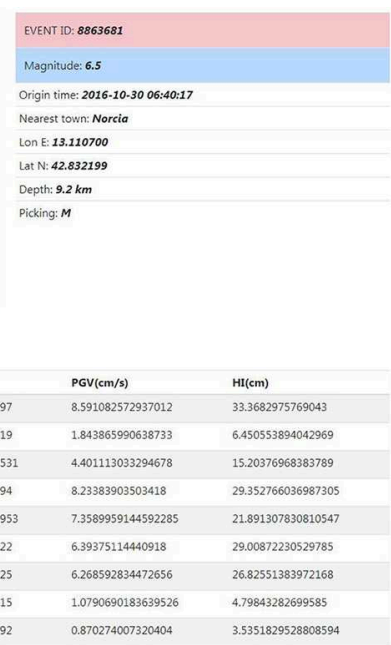

FIGURE 6 | Example of results after a seismic event, available for regional civil protection. Left: event panel of the SPB seismic stations that recorded seismic event. Right: event-station panel and strong motion parameters recorded at a single station. The color scale represents macroseismic intensity Imcs (light blue: V; yellow: VI; orange: VII) estimated by Faenza and Michelini (2010).

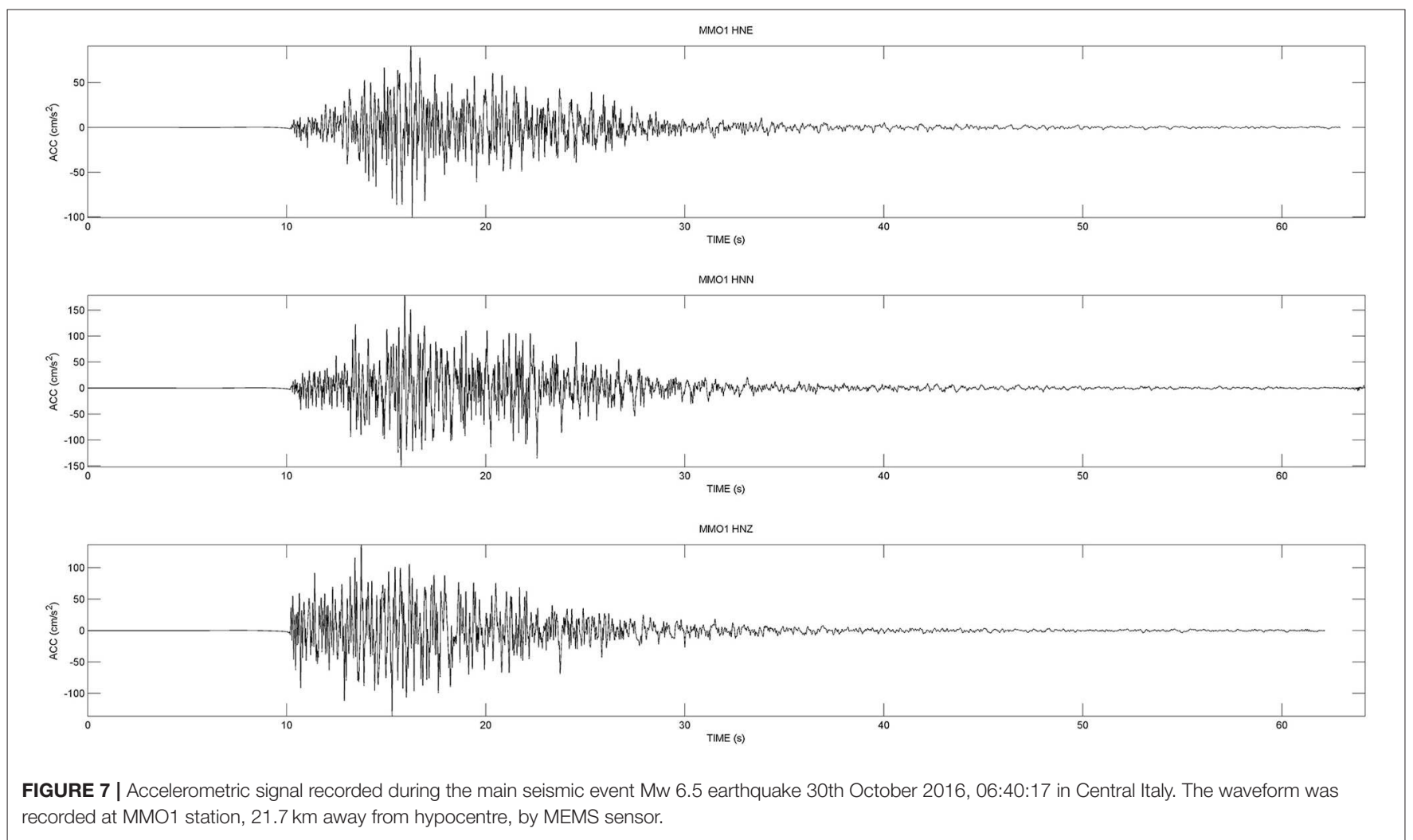


To date, the seismic network is composed of 19 instrumented SPBs. In most cases, the SPBs are town halls in small old villages, except for a school and a traffic police station. For each site, the information about geological and morphological characteristics allowed proposals for classifications of the various categories of the sites according to Italian Building Code (NTC2018 DM $17 / 01 / 2018,2018$ ) for the subsoil and topographical conditions. The characteristics of the building are obtained by Regione Marche that created a database of the SPB in the framework of seismic microzonation and analysis of the emergency limit conditions for the natural risks.

The continuous seismic data recorded by the 19 accelerometers are transmitted in real time and processed after the automatic detection of an earthquake by the acquisition system of the regional seismic network in Ancona ONT-INGV headquarter (Cattaneo et al., 2017). A time window containing the earthquake waveform is extracted: the start is $10 \mathrm{~s}$ before $\mathrm{P}$ arrival and the length is the double time of significant duration D, calculated from 5 to $95 \%$ of the Arias Intensity (Cauzzi et al., 2016). The time series extracted is processed to calculate strong motion engineering parameters at each station that recorded a local magnitude $\geq 3.0$ and a PGA $\geq 0.981 \mathrm{~cm} / \mathrm{s}^{2}(1 \mathrm{mg})$, that is an arbitrary threshold of the perception of a seismic event

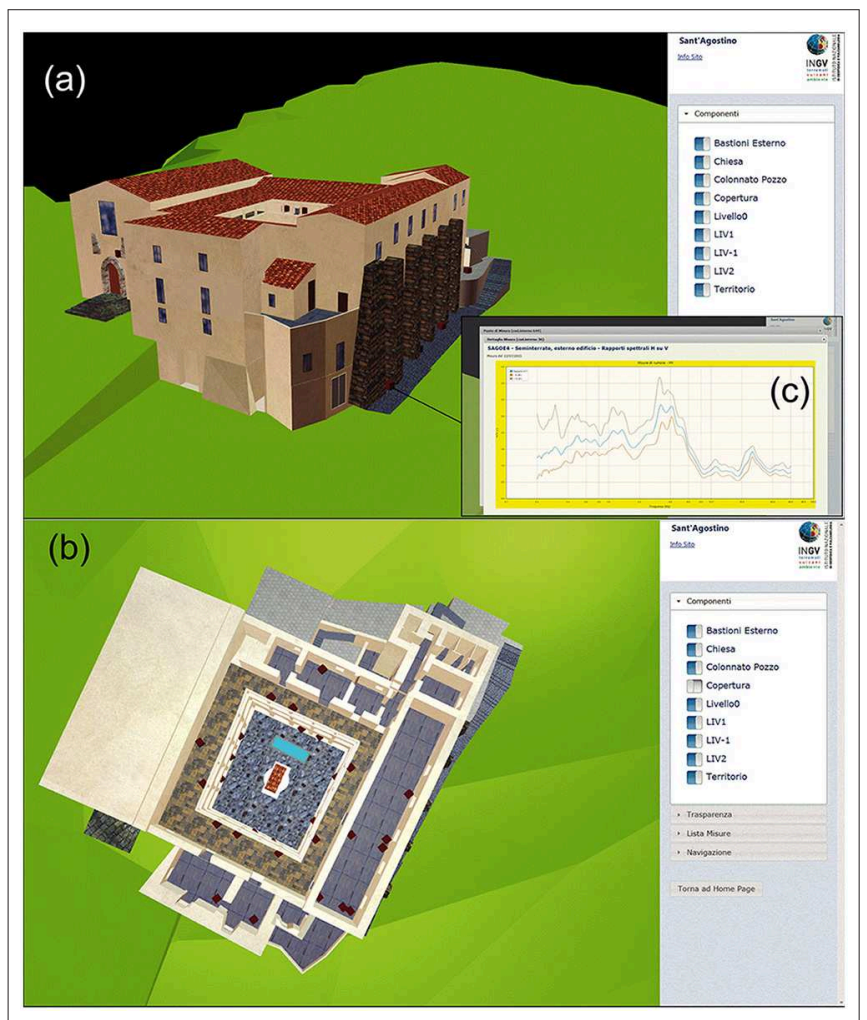

FIGURE 8 | Visual platform at building scale of the MASSIMO system: (a) view of the entire 3D model of the monumental complex of Sant'Agostino and (b) view from top excluding the roofs. The red cubes are the measurement points. (c) HVSR obtained by recording of ambient vibration for a point immediately outside the wall with buttresses. by peoples. A few minutes after the earthquake, the automatic procedures complete the waveform analysis and the regional civil protection officials have available the follow parameters (Figure 6): Peak Ground Acceleration (PGA), Peak Ground Velocity (PGV), Arias Intensity (AI), Housner Intensity (IH), Response Spectra at period $0.1,0.3,1$, and $3 \mathrm{~s}$.

The results are useful for applying a preliminary damage estimation based on empirical relationships. The simplest is an estimate of the macroseismic intensity (i.e., for Italy Faenza and Michelini, 2010). An alternative is the use of specific fragility curves supplied in the literature or obtained by Finite Element Models (FEM), if available, for more reliable estimates. Moreover, this kind of data could be implemented in a decision support system for the assessment and mitigation of seismic risk like, for example, CIPCast-ES developed by ENEA (Giovinazzi et al., 2017).

The results of the processing are archived in a relational database. The first seismic event processed occurred in the December 2013. At the date of June 2019, the database includes 95 seismic events; all of the information and their relevant results are provided in a web site, named MOSTspb (http://www.an.ingv. it/MOST), available only for regional civil protection officials. The magnitude of the events range between 3.0 (chosen as the lowest threshold) and 6.5 (earthquake recorded during the 20162017 seismic sequence of Central Italy), whereas the distances from epicenters range from 6.3 and $157.6 \mathrm{~km}$ and the distances from hypocenters range from 10.6 and $157.9 \mathrm{~km}$. Most of the earthquakes belong to the 2016-2017 seismic sequence in Central Italy. During the sequence, due to the high number of energetic events, the threshold of the analysis was increased to magnitude 4.0. The number of unanalyzed data in the magnitude range 3.03.9 is about 900 earthquakes: these events were not processed in real time and thus they do not currently appear in the database. In the database, the bigger Peak Ground Acceleration (PGA) is 178.5 $\mathrm{cm} / \mathrm{s}^{2}$ recorded during the main seismic event of the sequence (Mw 6.5, 30th October $2016=06: 40: 17$ UTC) at $21.7 \mathrm{~km}$ of hypocentral distance (Figure 7).

\section{STRUCTURAL CULTURAL HERITAGE MONITORING}

As previously recalled, the recent earthquakes have brought to light the need for an extensive monitoring and safety assessment of historic Italian construction heritage; in fact, ancient masonry buildings, although often being able to withstand vertical overload, can often not bear the horizontal forces produced by earthquakes. Therefore, the historic built heritage is particularly prone to significant damage during moderate to severe earthquakes. Moreover, the preservation and protection of historic heritage buildings are not only a cultural demand, but also an economic and social need to support the development of local communities. Nevertheless, the assessment of the seismic vulnerability of ancient masonry buildings remains a challenge. Indeed, if the structural behavior of new structures is a relatively simple task, it is more complicated to assess that of historic buildings, because of several uncertainties that affect the 
geometrical and mechanical properties of the structural elements (Betti and Galano, 2012; Betti et al., 2015; Clementi et al., 2017; Bartoli et al., 2018; Azzara et al., 2019).

It is worth mentioning that the use of finite element methods is often highly recommended in order to predict seismic behavior of monumental masonry structures (Formisano et al., 2018). The FEM-based methods for the non-linear analysis of masonry structures fall within two main approaches, referred to as macro-modeling and micro-modeling. In summary, the macro-modeling approach can be used on large structural members or full structures, and units (bricks and/or stones), mortar joints and interfaces are globally represented by single continuous elements. On the other hand, this approach may offer an adequate characterization of the structural response of the entire monumental building. Instead, in the micromodeling strategy, the units and mortar joints are represented

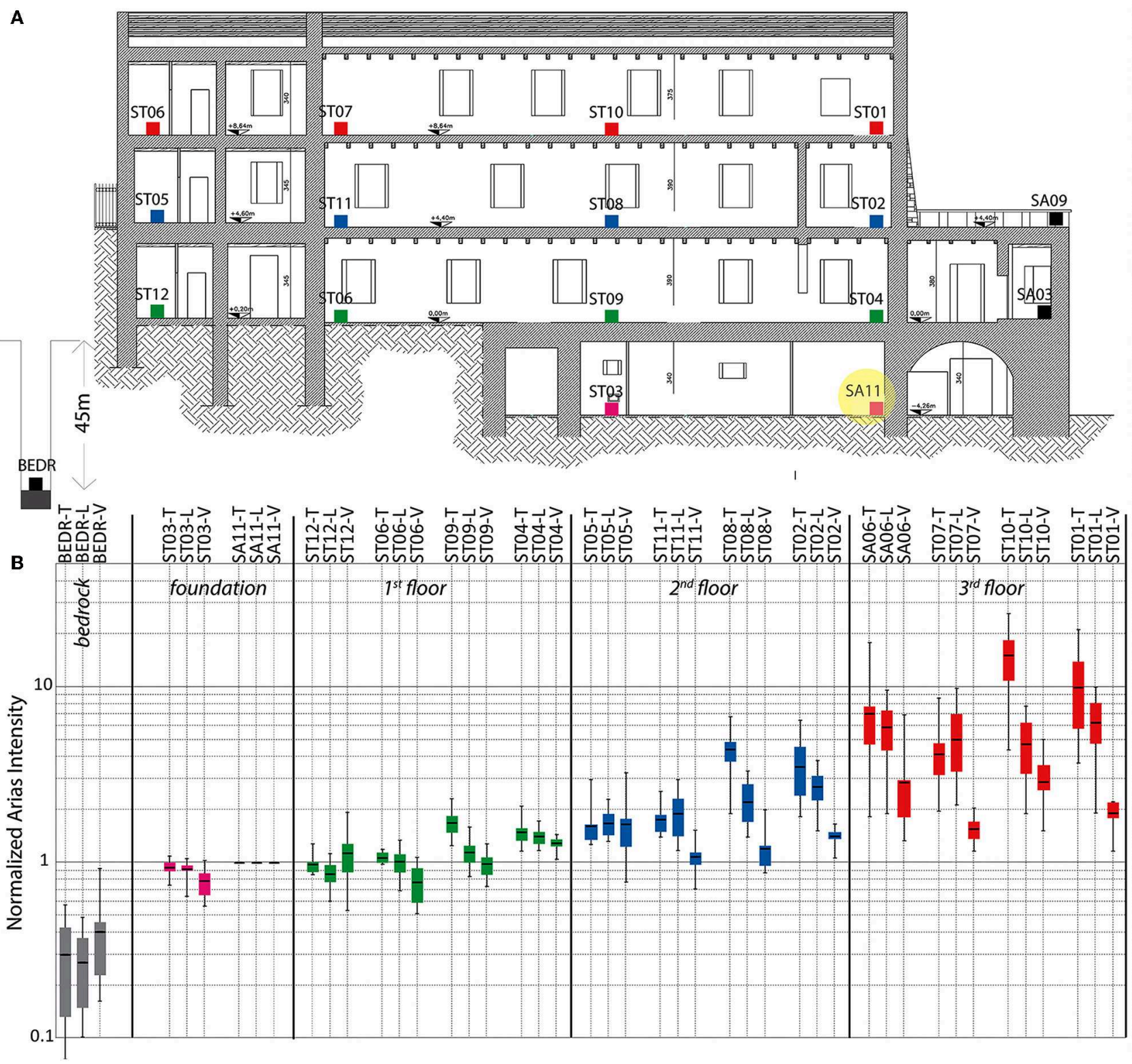

FIGURE 9 | Arias intensities at the sites normalized respect to that at the base (SA11). The Arias intensities were obtained by acceleration time histories filtered with acausal bandpass Butterworth filter of 4 th order in the band $0.1-10 \mathrm{~Hz}$. (A) The colored square represents the location of the seismic stations for each floor reported on the section of the wall. (B) The colored box represents the confidence (between 25th and 75th percentile) and the thick black line is the median, whereas the thin black lines are the range between maximum and minimum. The normalized Arias intensities are reported for each site and component $(T$, transverse; $L$, longitudinal; $V$, vertical). 
by continuous elements and are modeled separately (Betti et al., 2016). This detailed method is particularly adequate to describe the local response of the materials, also if a good knowledge about properties of each constituent and the interface is needed. Nevertheless, the intensive computational effort limits applicability of micro-models to the analysis of small elements or small structural details (Roca et al., 2010). An extensive analysis about structural methods to characterize the behavior of historical masonry buildings may be found in the literature (e.g., Roca et al., 2010; Betti et al., 2016; Castori et al., 2017; D’Altri et al., 2019).
In this context, the INGV developed the MASSIMO system (https://ponmassimo.rm.ingv.it/portal) which is able to gather, put together and make information available from different sources, which can be useful in monitoring the state of a historical buildings located in areas with high seismic hazards. The system integrates data from geophysical, remote sensing and non-destructive tools with those obtained by in-situ surveys and laboratory tests, in order to support multi-spatial and multi-temporal monitoring (Montuori et al., 2016). In addition, a $3 \mathrm{D} / 4 \mathrm{D}$ visual platform was developed through a dedicated manager software for the visualization and the use of data

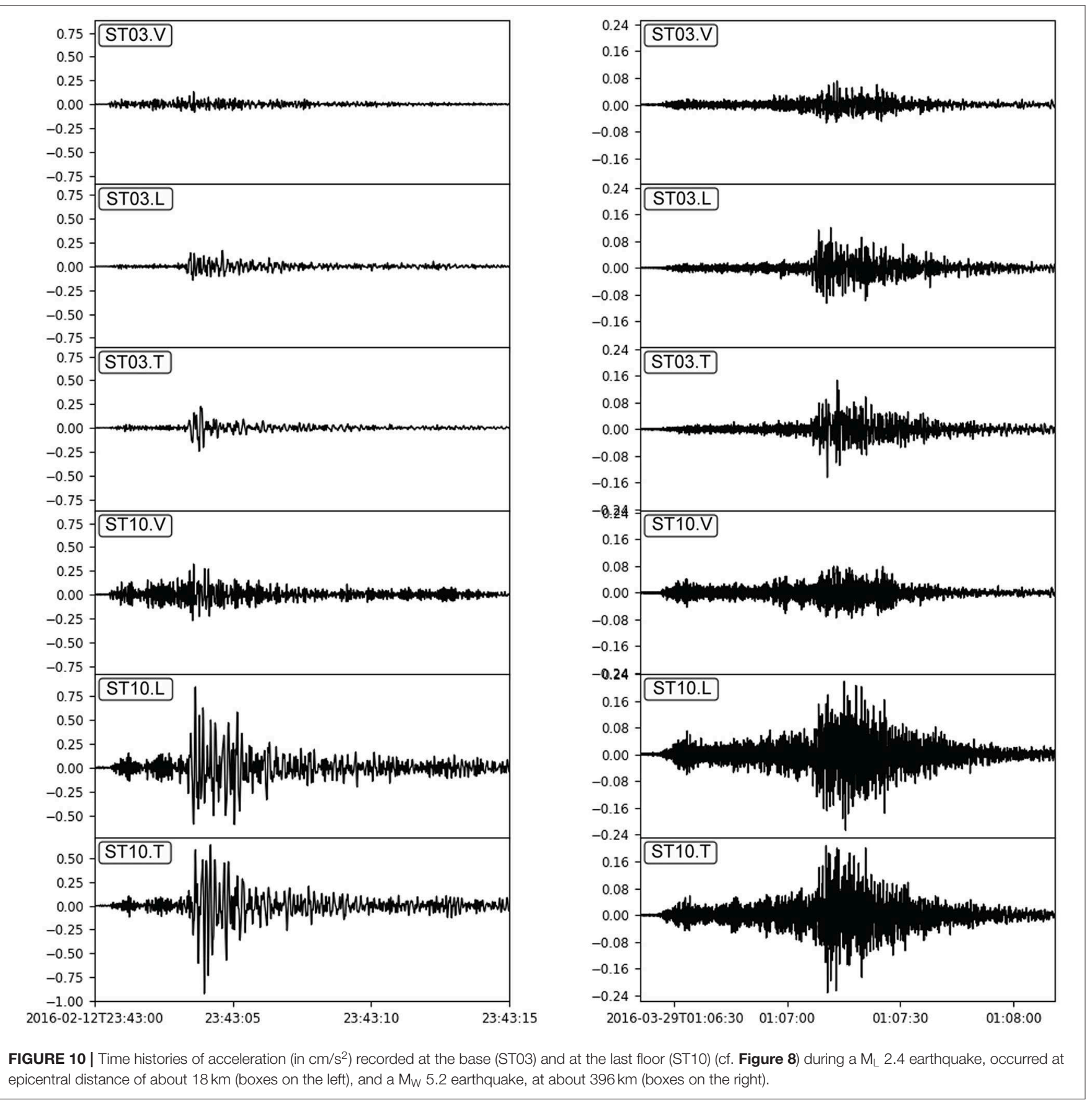


coming from the building-scale \& near-real-time surveys of monitored buildings. The platform is accessible through a webbased interface within conventional client-server architecture. The end-user may have access to the platform by connecting to a server application through web-browser and common Internet protocols. The platform allows the interactive navigation of the structure within a 3D spatial domain. Each geometrical element can be modified dynamically and contain information about attributes coming from multi-disciplinary investigations. This aspect justifies the $4 \mathrm{D}$ nature of the platform. The data can be provided on high definition monitors and with stereoscopic display functionalities. To implement this system, some test sites were selected in Calabria (Figure 2), including the monumental complex of Sant'Agostino in the city of Cosenza, which, built as convent in 1507, suffered significant damage and changes following different earthquakes. Today the structure hosts the Civic Museum of Brettii and Enotri. A detailed 3D model of the monumental complex was reconstructed through an extended measurement campaign using a terrestrial laser scanning technique (Costanzo et al., 2015), whereas a simplified sketch of the model was implemented with texture features, structural components, building layers and the location of measurement points in order to represent all information (Figures 8a,b). Each measurement point can be selected dynamically to show relevant results achieved through building-scale investigations and is properly stored in the MASSIMO repository. By way of example, the same Figure shows a measurement of ambient vibration expressed in term of HVSR (Figure 8c) immediately outside the wall with the buttresses, which can be directly accessed by clicking on the red cube.

After an extensive campaign to record ambient vibration at the different floors of the monumental complex and immediately outside it, the INGV deployed a seismic network along the largest external wall, that is characterized by significant variability in the HVSR curves obtained at the last floor along its extension. In the subsequent construction phases, the wall was consolidated with six buttresses built for about $3 / 4$ of its height. During the development of the MASSIMO system and until August 2016, the network was composed of 16 seismic stations (see Figure 9A), each consisting of a CENTAUR-6 or GAIA-2 seismic digitizer equipped with a TRILLIUM compact-20s broadband seismometer and a TITAN accelerometric transducer. Data was sampled at $100 \mathrm{~Hz}$ using 24-bit analog-to digital converters and time synchronism was provided by the embedded GPS system for the GAIA-2 digitizers and through a time-master for the CENTAUR-6. Practically, only one seismic station acquires the time and transfers it to the others. The continuous monitoring and transmission in real-time has allowed 10 earthquakes to be recorded in only 4 months (between January and April, 2016) with a good signal-to-noise ratio, considering that both small earthquakes (local magnitude, ML between 2.4 and 2.7) locally occurred and moderate earthquakes (moment magnitude, $\mathrm{M}_{\mathrm{W}}$ between 4.1 and 5.2) with epicenters in the Mediterranean area. All of these earthquakes, however, produced low intensity seismic records at the base of the structure. By analyzing the recordings, the energy content at the different floors of the wall was computed through the Arias intensity (AI), considering the variation of the motion in terms of amplification, frequency content and duration, simultaneously. The normalized Arias intensity (AIN), as a ratio between $\mathrm{AI}$ at a site and that at the reference site (station SA11), for each earthquake and component is reported in Figure 9B. The values of AIN were obtained by acceleration time histories filtered with an acausal bandpass Butterworth filter of the 4 th order in the band $0.1-10 \mathrm{~Hz}$. In Figure $9 B$, AIN is plotted in a logarithmic scale, identifying the range between the 25th and the 75th percentile (colored box) and median value (thick horizontal black line). To be thorough, in the same Figure, the minimum and maximum values are also reported (thin black line). The ratio shows amplification factors between 10 and 14 at the 3 rd floor on the transverse components; whereas, the factor assumes a value up to about 3 on the vertical components.

As a useful comparison, the same ratio was also calculated by the waveforms recorded at the bedrock; in fact, the INGV installed a seismic station near the historic city center of Cosenza, in a borehole at a depth of about $43 \mathrm{~m}$ from the surface were the metamorphic substrate was encountered. It should be noted that the energy content obtained by the horizontal components increases about three times at the base of the wall in respect to that measured at the bedrock and even 30 times at the last floor. The shaking is affected either by soil local response or soilstructure interaction; moreover, further amplifications can be due to the response of the structure itself.

In Figure 10, the acceleration time histories recorded at the base (ST03) and at the last floor (ST10) of the structure are shown with reference to two of the seismic events: a $M_{L}$ 2.4 earthquake occurred at an epicentral distance of about

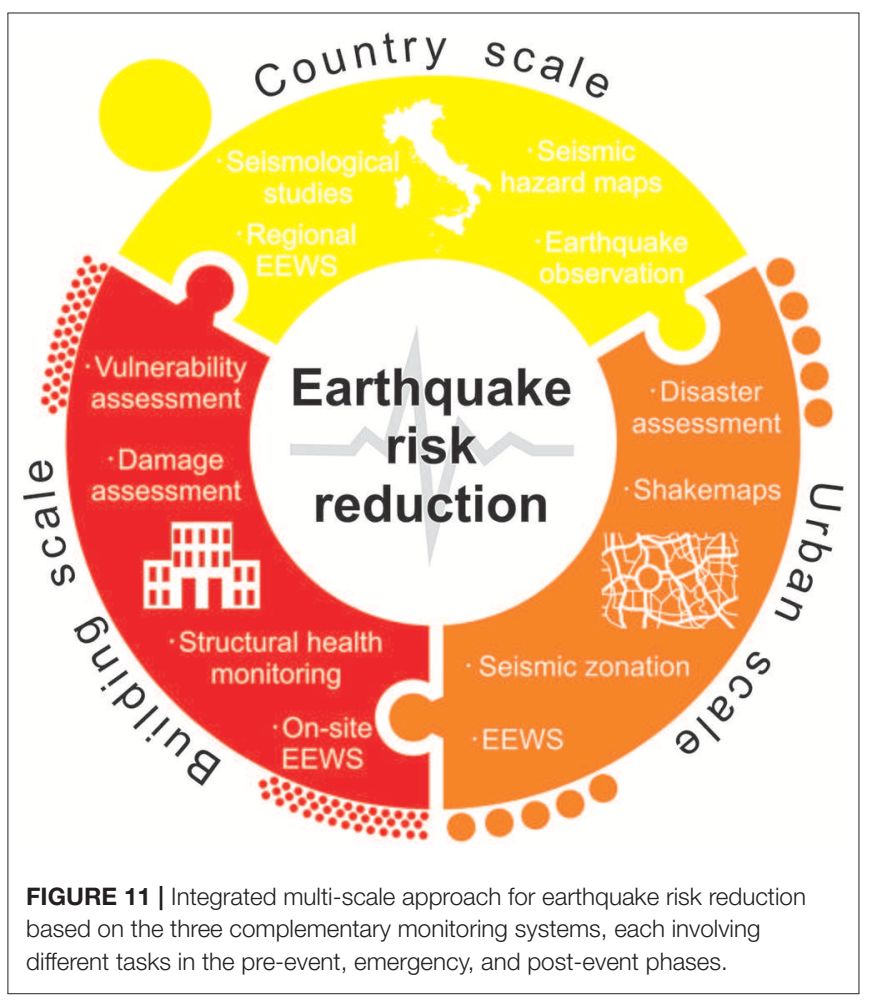


$18.3 \mathrm{~km}$ from the historical building (and depth of $8.2 \mathrm{~km}$ ) and a Mw 5.2 with an epicenter $396.2 \mathrm{~km}$ away (and depth of $10.1 \mathrm{~km}$ ). The waveforms clearly show the effects due to the structural response on the amplitudes of the seismic motion, with the maximum values significantly increasing in the horizontal components (up to about four times for the nearest earthquake).

At present, the seismic network is operating, although, from September 2016, the number of seismic stations was reduced. Today four GAIA 2 digitizers equipped with a TITAN accelerometer ensure the monitoring of the historical complex and the data storage into the database server of the Rende ONT-INGV headquarter. The data could be used to analyze any effects on the structural response following natural events (e.g., any earthquakes) or anthropic interventions (e.g., consolidation works).

\section{CONCLUSIVE REMARKS}

The ONT-INGV has been recently involved in several projects devoted to the reduction of seismic risks in Italy by means of the implementation of urban-scale and building-scale monitoring networks. Such systems also represent a support for the well-established national seismic network. All of these three approaches (country, urban, and building scale) could be framed within a unique system in which each part is responsible for different tasks, with the common final objective of the earthquake risk reduction.

Nowadays almost every country in the world has its own national seismic network for earthquake detection, and, most of all, they are essential tools for the seismic hazard assessment. Conversely, the urban networks have only been developed recently and have mostly been carried out as experimental or temporary systems. In Italy, where the historical city centers are usually highly vulnerable, it should be considered as an opportunity to establish urban networks, at least the most hazardous zones. They allow the rapid post-earthquake disaster assessment and a more effective emergency management. The value of building monitoring has long been recognized as important, but strongly limited because of the costs and of the logistic difficulties to maintain long-term campaigns. Structural health monitoring of buildings is a fundamental tool in Italy, a country which has a significant historical heritage. Building monitoring must also consider strategic public buildings, especially in the most vulnerable areas, to integrate and support conservation strategies and to preserve their strategic function (i.e., security, management, and organization) and their cultural value in case of destructive earthquakes.

Because each approach has its own importance, the three systems should not be considered as mutually alternative for the earthquake risk reduction, they should rather be integrated as a unique, multi-scale system (Figure 11). They all contribute, each with its own characteristics, in the pre-event phase, in the emergency-response phase when the priority is the safeguarding of human life, and in the post-event phase. The potential outcomes of an integrated multi-scale system for earthquake risk reduction is left to the civil society, the civil protection and decision makers, and the scientific community.

The first steps toward integration would be to adopt standardized data formats which ease the sharing of the data between different sources, and to collect the data into unique platforms. Such databases allow the effective data processing for the production of impact and damage models, which, in turn, provide new capabilities for the simulation of complex crisis scenario (c.f. Rome et al., 2016; Giovinazzi et al., 2017). The authority in charge of risk management would benefit before the event in terms of improving prevention and preparedness to the disasters, and after the event because the information distributed from these networks will provide decisive support for decisions making on the appropriate response actions. The same monitoring network could be employed in the implementation of EEWS with clear benefits in term of risk awareness, and a reduction of exposure in case of strong earthquakes. Finally, sciences in terms of seismology, earthquake and geotechnical engineering, will benefit from all of the collected data. Large datasets at multi-scale resolution represent a great opportunity to study earthquakes and seismic sources, to map site amplification effects, to assess the interaction between ground-shaking and structures, and much more.

\section{DATA AVAILABILITY STATEMENT}

The datasets generated for this study are available on request to the corresponding author.

\section{AUTHOR CONTRIBUTIONS}

AD'A: conceptualization. AD'A, AC, MC, and SM: methodology. AD'A, SSc, AC, SM, SSt, and CD: validation. CL, SSc, and GV: investigation. GV, CL, SF, and CL: resources. AD'A, GV, CL, $\mathrm{AC}, \mathrm{SF}$, and CL: data analysis and curation. GV, SM, SF, and CL: hardware implementation. GV, SM, SF, and CL: software implementation. AD'A, AC, SSc, MC, GV, SM, SF, and CL: network implementation. AD'A, SSc, AC, and SM: writingoriginal draft preparation. AD'A, SSc, AC, and SM: writingreview and editing. AD'A, SSt, and CD: supervision. AD'A, MC, FB, SSt, and CD: project administration. AD'A, MC, FB, SSt, and $\mathrm{CD}$ : funding acquisition. All authors: contributed to manuscript revision, read, and approved the submitted version.

\section{FUNDING}

This work was supported by the MEMS (Monitoring of Earthquakes through MEMS Sensors) project, funded by Vulcanologia (2018). The MASSIMO system was supported and funded by the Italian Ministry of Education, University and Research (MIUR) under the research project PON0102710 MASSIMO - Monitoraggio in Area Sismica di SIstemi MOnumentali. IPA Adriatic Holistic and Readiness Interreg Italy-Croatia funded by European Union and Agreement between Civil Protection of the Regione Marche authority and INGV. 


\section{ACKNOWLEDGMENTS}

The authors thank Roberto D'Anna, Massimo Frapiccini, Fabio Di Gangi, Giancarlo Monachesi, Debora Pantaleo,

\section{REFERENCES}

Ahern, T., Casey, R., Barnes, D., Benson, R., and Knight, T. (2007). SEED Standard for the Exchange of Earthquake Data Reference Manual Format Version 2.4. Incorporated Research Institutions for Seismology (IRIS), Seattle.

Ambraseys, N. (1975). "The correlation of intensity with ground motion," in Proceedings of the 14th European Conference Seismic Commission, Vol. 1 (Trieste), 335-341.

Andreini, M., De Falco, A., Giresini, L., and Sassu, M. (2014). Structural damage in the cities of Reggiolo and Carpi after the earthquake on May 2012 in Emilia Romagna. Bull. Earthq. Eng. 12, 2445-2480. doi: 10.1007/s10518-014-9660-7

Azzara, R. M., Girardi, M., Padovani, C., and Pellegrini, D. (2019). Experimental and numerical investigations on the seismic behaviour of the San Frediano bell tower in Lucca. Ann. Geophys. 61:AC59. doi: 10.4401/ag-8025

Bartoli, G., Betti, M., Marra, A. M., and Monchetti, S. (2018). A Bayesian model updating framework for robust seismic fragility analysis of nonisolated historic masonry towers. Philos. Trans. R. Soc. A 377:20190024. doi: 10.1098/rsta.2019.0024

Betti, M., and Galano, L. (2012). Seismic analysis of historic masonry buildings: the vicarious palace in Pescia (Italy). Buildings 2, 63-82. doi: 10.3390/buildings2020063

Betti, M., Galano, L., and Vignoli, A. (2015). Time-history seismic analysis of masonry buildings: a comparison between two non-linear modelling approaches. Buildings 5, 597-621. doi: 10.3390/buildings5020597

Betti, M., Galano, L., and Vignoli, A. (2016). "Finite Element Modelling for Seismic Assessment of Historic Masonry Buildings," in Earthquakes and Their Impact on Society, Springer Natural Hazards. ed S. D’Amico (Cham: Springer), 377-415. doi: 10.1007/978-3-319-21753-6_14

Cannioto, M., D’Alessandro, A., Lo Bosco, G., Scudero, S., and Vitale, G. (2017). Vehicle routing problem and UAV application in the post-earthquake scenario. Nat. Hazards Earth Syst. Sci. 17, 1939-1946. doi: 10.5194/nhess-17-1939-2017

Caserta, A., Doumaz, F., Costanzo, A., Gervasi, A., Thorossian, W., Falcone, S., et al. (2016). Assessing soil-structure interaction during the 2016 central Italy seismic sequence (Italy): preliminary results. Ann. Geophys. 59, 1-7. doi: $10.4401 /$ ag-7250

Casolo, S. (2001). Significant ground motion parameters for evaluation of the seismic performance of slender masonry towers. J. Earthq. Eng. 5, 187-204. doi: 10.1080/13632460109350391

Castori, G., Borri, A., De Maria, A., Corradi, M., and Sisti, R. (2017). Seismic vulnerability assessment of a monumental masonry building. Eng. Struct. 136, 454-465. doi: 10.1016/j.engstruct.2017.01.035

Cattaneo, M., Frapiccini, M., Ladina, C., Marzorati, S., and Monachesi, G. (2017). A mixed automatic-manual seismic catalog for Central-Eastern Italy: analysis of homogeneity. Ann. Geophys. 60:S0667. doi: 10.4401/ag-7333

Cauzzi, C., Sleeman, R., Clinton, J., Ballesta, J. D., Galanis, O., and Kästli, P. (2016). Introducing the European rapid raw strong-motion database. Seismol. Res. Lett. 87, 977-986. doi: 10.1785/0220150271

Chiauzzi, L., Masi, A., Mucciarelli, M., Vona, M., Pacor, F., Cultrera, G., et al. (2012). Building damage scenarios based on exploitation of Housner intensity derived from finite faults ground motion simulations. Bull. Earthq. Eng. 10, 517-545. doi: 10.1007/s10518-011-9309-8

Chung, A., Neighbors, C., Belmonte, A., Miller, M., Sepulveda, H. H., Christensen, C., et al. (2011). The Quake-Catcher Network rapid aftershock mobilization program following the 2010 M 8.8 Maule, Chile earthquake. Seismol. Res. Lett. 82, 526-532. doi: 10.1785/gssrl.82.4.526

Clayton, R. W., Heaton, T., Chandy, M., Krause, A., Kohler, M., Bunn, J., et al. (2012). Community seismic network. Ann. Geophys. 54. doi: 10.4401/ag-5269

Clementi, F., Quagliarini, E., Monni, F., Giordano, E., and Lenci, S. (2017). Cultural heritage and earthquake: the case study of "Santa Maria della Carità" in Ascoli Piceno. Open Civil Eng. J. 11, 1079-1105. doi: 10.2174/1874149501711011079
Giuseppe Passafiume, Paolo Sandroni, Stefano Speciale, Francesca Sini, and Gabriella Speranza for their support in the urban e structural network implementation e cultural heritage investigation.

Cochran, E. S., Lawrence, J. F., Christensen, C., and Jakka, R. S. (2009). The quakecatcher network: citizen science expanding seismic horizons. Seismol. Res. Lett. 80, 26-30. doi: 10.1785/gssrl.80.1.26

Costanzo, A., Minasi, M., Casula, G., Musacchio, M., and Buongiorno, M. F. (2015). Combined use of terrestrial laser scanning and IR thermography applied to a historical building. Sensors 15, 194-213. doi: 10.3390/s150100194

Crawford, R., and Ward, H. S. (1964). Determination of the natural periods of buildings. Bull. Seism. Soc. Am. 54, 1743-1756.

D'Alessandro, A. (2014). Monitoring of earthquakes using MEMS sensors. Curr. Sci. 107, 733-734. Available online at: http://jstor.org/stable/i24105516

D'Alessandro, A. (2016). Tiny accelerometers create Europe's first urban seismic network. EOS 97, 16-20. doi: 10.1029/2016EO048403

D'Alessandro, A., and D'Anna, G. (2013). Suitability of low cost 3 axes MEMS accelerometer in strong motion seismology: tests on the LIS331DLH (iPhone) accelerometer. Bull. Seismol. Soc. Am. 103, 2906-2913. doi: 10.1785/0120120287

D’Alessandro, A., D’Anna, R., Greco, L., Passafiume, G., Scudero, S., Speciale, S., et al. (2018a). "Monitoring earthquake through MEMS sensors (MEMS project) in the town of Acireale (Italy)," in 5th IEEE International Symposium on Inertial Sensors and Systems, Conference Paper, INERTIAL 2018 (Como), 4. doi: 10.1109/ISISS.2018.8358143

D’Alessandro, A., Greco, L., Scudero, S., Siino, M., Vitale, G., D’Anna, R., et al. (2019a). Sviluppo di una stazione sismica low-cost basata su tecnologia MEMS. Quaderni di Geofisica 153, 1-60. Available online at: http://editoria.rm.ingv.it/ quaderni/2019/quaderno153/

D’Alessandro, A., Luzio, D., and D’Anna, G. (2014). Urban MEMS based seismic network for post-earthquakes rapid disaster assessment. Adv. Geosci. 40, 1-9. doi: 10.5194/adgeo-40-1-2014

D’Alessandro, A., Luzio, D., D’Anna, G., and Mangano, G. (2011). Seismic network evaluation through simulation: an application to the Italian National Seismic Network. Bull. Seismol. Soc. Am. 101, 1213-1232. doi: 10.1785/0120100066

D'Alessandro, A., Scudero, S., and Vitale, G. (2019b). A review of the capacitive MEMS for seismology. Sensors 19, 1-22. doi: 10.3390/s19143093

D’Alessandro, A., Vitale, G., Scudero, S., D’Anna, R., Costanza, A., Fagiolini, A., et al. (2017). "Characterization of MEMS accelerometer self-noise by means of PSD and Allan Variance analysis," in 7th International Workshop on Advances in Sensors and Interfaces - Conference Paper, IWASI 2017 (Vieste, Italy), 159-164. doi: 10.1109/IWASI.2017.7974238

D’Alessandro, A., Vitale, G., Scudero, S., D’Anna, R., Passafiume, G., Greco, L., et al. (2018b). "Real-time urban seismic network and structural monitoring by means of accelerometric sensors: application to the historic buildings of Catania (Italy)," in IEEE International Conference on Environmental Engineering, Conference Paper, EE 2018 (Milan), 1-5. doi: 10.1109/EE1.2018.8385254

D’Altri, A. M., Sarhosis, V., Milani, G., Rots, J., Cattari, S., Lagomarsino, S., et al. (2019). "Chapter 1 - A review of numerical models for masonry structures," in Woodhead Publishing Series in Civil and Structural Engineering, Numerical Modeling of Masonry and Historical Structures, eds B. Ghiassi and G. Milani (Cambridge, UK: Woodhead Publishing), 3-53. doi: 10.1016/B978-0-08-102439-3.00001-4

D'Ayala, D. F., and Paganoni, S. (2011). Assessment and analysis of damage in L'Aquila historic city centre after 6th April 2009. Bull. Earthq. Eng. 9, 81-104. doi: 10.1007/s10518-010-9224-4

Dolce, M., Nicoletti, M., De Sortis, A., Marchesini, S., Spina, D., and Talanas, F. (2017). Osservatorio sismico delle strutture: the Italian structural seismic monitoring network. Bull. Earthq. Eng. 15, 621-641. doi: 10.1007/s10518-015-9738-x

Dolce, M., Speranza, E., Bocchi, F., and Conte, C. (2019). Structural operational efficiency indices for Emergency Limit Condition (I.OPà.CLE): experiment results. Bollettino di Geofisica Teorica ed Applicata 60, 243-263. doi: $10.4430 /$ bgta0246 
Faenza, L., and Michelini, A. (2010). Regression analysis of MCS intensity and ground motion parameters in Italy and its application in ShakeMap. Geophys. J. Int. 180, 1138-1152. doi: 10.1111/j.1365-246X.2009.04467.x

Fiorentino, G., Forte, A., Pagano, E., Sabetta, F., Baggio, C., Lavorato, D., et al. (2018). Damage patterns in the town of Amatrice after August 24th, 2016 Central Italy earthquakes. Bull. Earthq. Eng. 16, 1399-1423. doi: 10.1007/s10518-017-0254-z

Formisano, A., Vaiano, G., and Fabbrocino, F., Milani, G. (2018). Seismic vulnerability of Italian masonry churches: the case of the Nativity of Blessed Virgin Mary in Stellata of Bondeno. J. Build Eng. 20, 179-200. doi: 10.1016/j.jobe.2018.07.017

Gallipoli, M. R., Mucciarelli, M., Castro, R. R., Monachesi, G., and Contri, P. (2003). Structure, soil-structure response and effects of damagebased on observations of horizontal-to-vertical spectral ratio of microtremors. Soil Dyn. Earthq. Eng. 24, 487-495. doi: 10.1142/S1363246903000948

Giordan, D., Hayakawa, Y., Nex, F., Remondino, F., and Tarolli, P. (2018). the use of remotely piloted aircraft systems (RPASs) for natural hazards monitoring and management. Nat. Hazards Earth Syst. Sci. 18, 1079-1096. doi: 10.5194/nhess-18-1079-2018

Giovinazzi, S., Di Pietro, A., Mei, M., Pollino, M., and Rosato, V. (2017). "Protection of critical infrastructure in the event of earthquakes: CIPCast-ES," in Atti del XVII Convegno ANIDIS Lingegneria Sismica in Italia (Pistoia), 17-21. Available online at: http://digital.casalini.it/4216197

Horiuchi, S., Horiuchi, Y., Yamamoto, S., Nakamura, H., Wu, C., Rydelek, P. A., et al. (2009). Home seismometer for earthquake early warning. Geophys. Res. Lett. 36. doi: 10.1029/2008GL036572

Lagomarsino, S. (2012). Damage assessment of churches after L'Aquila earthquake (2009). Bull. Earthq. Eng. 10, 73-92. doi: 10.1007/s10518-011-9307-x

Lagomarsino, S., and Giovinazzi, S. (2006). Macroseismic and mechanical models for the vulnerability and damage assessment of current buildings. Bull. Earthq. Eng. 4, 415-443. doi: 10.1007/s10518-006-9024-z

Margottini, C., Molin, D., and Serva, L. (1992). Intensity versus ground motion: a new approach using Italian data. Eng. Geol. 33, 45-58. doi: 10.1016/0013-7952(92)90034-V

Matassoni, L., Giovinazzi, S., Pollino, M., Fiaschi, A., La Porta, L., and Rosato, V. (2017). "A geospatial decision support tool for seismic risk management: Florence (Italy) case study," in Computational Science and Its Applications ICCSA 2017. ICCSA 2017. Lecture Notes in Computer Science, Vol. 10405, eds O. Gervasi, B. Murgante, S. Misra, G. Borruso, C. M. Torre, A. M. A. C. Rocha, et al. (Cham: Springer), 278-293. doi: 10.1007/978-3-319-62395-5_20

McNamara, D. E., and Buland, R. P. (2004), Ambient noise levels in the Continental United States. Bull. Seism. Soc. Am. 94, 1517-1527. doi: $10.1785 / 012003001$

Montuori, A., Costanzo, A., Gaudiosi, I., Vecchio, A., Pannaccione Apa, M. I., Gervasi, A., et al. (2016). The MASSIMO system for the safeguarding of historic buildings in a seismic area: operationally-oriented platforms. Eur. J. Remote Sens. 49, 397-415. doi: 10.5721/EuJRS20164922

Mucciarelli, M., Masi, A., Gallipoli, M. R., Harabaglia, P., Vona, M., Ponzo, F., et al. (2004). Analysis of RC building dynamic response and soil-building resonance based on data recorded during a damaging earthquake (Molise, Italy, 2002). Bull. Seism. Soc. Am. 94, 1943-1953. doi: 10.1785/012003186

Nakamura, Y. (1989). A method for dynamic characteristics estimation of subsurface using microtremor on the ground surface. QR Railway Tech. Res. Inst. 30, 25-33.

Nof, R. N., Chung, A. I., Rademacher, H., Dengler, L., and Allen, R. M. (2019). MEMS Accelerometer Mini-Array (MAMA): a low-cost implementation for earthquake earlywarning enhancement. Earthq. Spectra 35, 21-38. doi: 10.1193/021218EQS036M
NTC2018 DM 17/01/2018 (2018). Aggiornamento delle «Norme tecniche per le costruzioni $\gg$. Gazzetta Ufficiale 42 del 20/02/2018-supplemento ordinario n.8 (in Italian),

Pierleoni, P., Marzorati, S., Ladina, C., Raggiunto, S., Belli, A., Palma, L., et al. (2018). Performance evaluation of a low-cost sensing unit for seismic applications: field testing during seismic events of 2016-2017 in Central Italy. IEEE Sens. J. 18, 6644-6659. doi: 10.1109/JSEN.2018.2850065

Regni, M., Arezzo, D., Carbonari, S., Gara, F., and Zonta, D. (2018). Effect of environmental conditions on the modal response of a 10-story reinforced concrete tower. Shock Vibration. 2018:9476146. doi: 10.1155/2018/94 76146

Roca, P., Cervera, M., Gariup, G., and Pelà, L. (2010). Structural analysis of masonry historical constcructions. Classical and advanced approaches. Arch. Comput. Methods Eng. 17, 299-325. doi: 10.1007/s11831-010-9046-1

Rome, E., Doll, T., Rilling, S., Sojeva, B., Voß, N., and Xie, J. (2016). "The use of what-if analysis to improve the management of crisis situations," in Managing the Complexity of Critical Infrastructures, Studies in Systems, Decision and Control, Vol. 90, eds R. Setola, V. Rosato, E. Kyriakides, and E. Rome (Cham: Springer), 233-277. doi: 10.1007/978-3-319-51043-9_10

Satriano, C., Wu, Y. M., Zollo, A., and Kanamori, H. (2011), Earthquake early warning: concepts, methods and physical grounds. Soil Dyn. Earthq. Eng. 2011, 106-118. doi: 10.1016/j.soildyn.2010.07.007

Scudero, S., D'Alessandro, A., Greco, L., and Vitale, G. (2018). "MEMS technology in seismology: a short review," in Proceedings of the 2018 IEEE International Conference on Environmental Engineering (EE) (Milan), 1-5. doi: 10.1109/EE1.2018.8385252

Spence, R., and D'Ayala, D. (2018). Damage assessment and analysis of the 1997 Umbria-Marche earthquakes. Struct. Eng. Int. 9, 229-233. doi: 10.2749/101686699780482014

Trifunac, M. D., and Brady, A. G. (1975). On the correlation of seismic intensity scales with the peaks of recorded strong ground motion. Bull. Seism. Soc. Am. $65,139-162$.

Valente, M., Barbieri, G., and Biolzi, L. (2017). Damage assessment of three medieval churches after the 2012 Emilia earthquake. Bull. Earthq. Eng. 15, 2939-2980. doi: 10.1007/s10518-016-0073-7

Wald, D. J., Quitoriano, V., Heaton, T. H., and Kanamori, H. (1999). Relationships between peak ground acceleration, peak ground velocity, and modified Mercalli intensity in California. Earthq. Spectra 15, 557-564. doi: 10.1193/1. 1586058

Ward, H. S., and Crawford, R. (1966), Wind-induced vibrations and building modes. Bull. Seism. Soc. Am. 56, 793-813.

Zhu, M., Du, X., Zhang, X., Luo, H., and Wang, G. (2019). MultiUAV rapid-assessment task-assignment problem in a post-earthquake scenario. IEEE Access 7, 74542-74557. doi: 10.1109/ACCESS.2019. 2920736

Conflict of Interest: The authors declare that the research was conducted in the absence of any commercial or financial relationships that could be construed as a potential conflict of interest.

Copyright $\odot 2019$ D’Alessandro, Costanzo, Ladina, Buongiorno, Cattaneo, Falcone, La Piana, Marzorati, Scudero, Vitale, Stramondo and Doglioni. This is an openaccess article distributed under the terms of the Creative Commons Attribution License (CC BY). The use, distribution or reproduction in other forums is permitted, provided the original author(s) and the copyright owner(s) are credited and that the original publication in this journal is cited, in accordance with accepted academic practice. No use, distribution or reproduction is permitted which does not comply with these terms. 